Original research

\title{
Feasibility Study on the Use of Modified Copper Slag as a Sustainable Fine Aggregate in Mortar
}

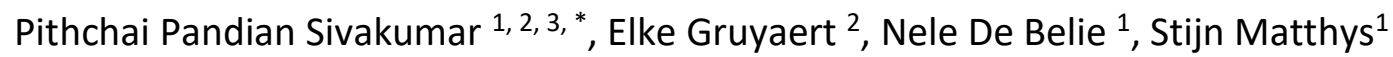

1. Magnel-Vandepitte Laboratory for Structural Engineering and Building Materials, Ghent University, Technologiepark Zwijnaarde 60, BE-9052 Ghent, Belgium; E-Mails: Pithchaipandian.sivakumar@ugent.be; nele.debelie@ugent.be; stijn.matthys@ugent.be

2. KU Leuven, Department of Civil Engineering, Materials and Constructions, Ghent Technology Campus, Gebroeders De Smetstraat 1, BE-9000 Ghent, Belgium; E-Mail: elke.gruyaert@kuleuven.be

3. SIM vzw, Technologiepark 48, BE-9052 Zwijnaarde, Belgium

* Correspondence: Pithchai Pandian Sivakumar; E-Mail: Pithchaipandian.sivakumar@ugent.be

Academic Editor: Aritra Ghosh

Special Issue: Wastes, Residues and Byproducts for the Production of Construction Materials

Recent Progress in Materials

2021, volume 3, issue 2

doi:10.21926/rpm.2102022
Received: March 09, 2021

Accepted: May 20, 2021

Published: June 01, 2021

\section{Abstract}

Depending on the availability of aggregate sources pertaining to their geographic locations, the concrete industry utilizes conventional aggregates such as marine sand, dredged gravel, or crushed rocks. This method requires high energy and high processing costs for washing and grinding. The objective of this work is to use Modified Ferro silicate slag (MFS), a by-product obtained from the copper industry, as an alternative to the conventional fine aggregates found in mortar. No additional processing such as washing or grinding is required. By using the MFS slag as an aggregate in mortar or concrete, the factors of sustainability and a circular economy are enhanced. The current study focuses on the characterization of the MFS slag, including the mortar mixes with the MFS slag as a fine aggregate, and shows that the MFS slag can be a promising raw material to replace conventional aggregates in mortar. The leaching of its heavy elements such as $\mathrm{Sb}, \mathrm{As}, \mathrm{Cr}, \mathrm{Mo}, \mathrm{Pb}$, and $\mathrm{Zn}$ was conducted well within limits

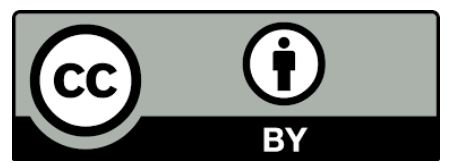
conditions of the Creative Commons by Attribution License, which permits unrestricted use, distribution, and reproduction in any medium or format, provided the original work is correctly cited. 
(VLAREMA 4). The SEM and MIP analyses indicated that the porosity of the MFS slag mortar was higher compared to the standard aggregate mortar. Moreover, the MFS slag mortar showed acceptable resistance toward the alkali-silica reaction and carbonation.

\section{Keywords}

MFS slag; aggregate; microstructure; leaching, compressive strength; sustainability.

\section{Introduction}

On the one hand, due to growing concern over global warming and climate change, there is increased pressure on the construction industry for using sustainable building materials. Concrete is one of the main materials used in the construction industry, and its aggregates form the major component in it. Depending upon the availability of the aggregate in specific geographic locations, the construction industry uses conventional aggregates such as marine sand, dredged gravel or crushed rocks, often granite or limestone [1]. These conventional aggregates are usually extracted from natural resources, further depleting them [2].

On the other hand, an increased demand for copper $(\mathrm{Cu})$ metal in the world market has resulted in pyro-metallurgical industries producing $\mathrm{Cu}$ metal on a large scale. Pyro-metallurgy processes involve the oxidation and reduction of the copper ore or scrap in a smelter [3]. As a result, two separable liquid layers of Cu rich matte and slag (oxides) are formed [4]. When the slag is discharged from the furnace and cooled with water, it forms a glassy and dissolvable structure. It has been estimated that the annual production of $\mathrm{Cu}$ slag has reached approximately 24.6 million tons worldwide, 5.56 million tons in Europe, and 180-kilo tons in Belgium [5-7]. This Cu slag is mostly land-filled or used in a limited number of applications, such as for sandblasting industries and the manufacturing of abrasive tools [8].

Usage of industrial by-products such as the ground granulated blast furnace slag (GGBFS) fly ash (FA), and silica fume (SF) as supplementary cementitious materials (SCM) is well appreciated among environmentalists. A wide range of studies, including Cu slag as a partial replacement for cement in concrete, displayed interesting results due to its glassy structure, which mainly contains the oxides of $\mathrm{Fe}, \mathrm{Si}$, and $\mathrm{Al}$. For instance, when $\mathrm{Cu}$ slag is used as a substitute for cement in concrete, the $\mathrm{Si}$ rich glass structure reacts with the porous alkaline solution (enriched in $\mathrm{CH}$ ) as a result of the pozzolanic reaction. In the work of Sivakumar et al., the pozzolanic reactivity of one particular type of clean Cu slag as SCM was assessed using TGA analysis by replacing $0 \%, 15 \%, 30 \%$, and $50 \%$ of CEM I in a paste [9]. The conclusions were that the $\mathrm{CH}$ was consumed through the pozzolanic reaction. $\mathrm{Cu}$ slag is mostly land-filled but could be a promising candidate as a partial/full replacement for cement.

Literature has already shown that the $\mathrm{Cu}$ slag could qualify as a promising candidate for a fine aggregate in both mortar and concrete [10-15]. In work performed by Al-Jabri et al., the workability and compressive strength of high-performance concrete $(w / c=0.35)$ was investigated using Cu slag as fine aggregate [16]. The authors stated that the workability of the concrete tends to improve with the increase in the addition of the Cu slag and concluded that $50 \%$ of the Cu slag substitution was presented with the highest compressive strength after 28 days. In addition, Ishimaru et al. 
investigated the basic properties of concrete using $\mathrm{Cu}$ slag as the fine aggregate [12]. The final observations of the author were that up to $20 \%$ (in volume) of Cu slag used as fine aggregate served as an ideal replacement level. Moreover, Wu et al. studied the dynamic compression behavior of the concrete reinforced by $\mathrm{Cu}$ slag [17]. The study showed that the $\mathrm{Cu}$ slag reinforced the concrete with a $20 \%$ replacement and generally showed improved mechanical properties compared to the reference concrete having standard aggregate. Note that other industrial by-products have been widely used as fine aggregate replacements. Shi et al. used air-cooled blast furnace slag (ACBFS) as a high volume replacement for fine aggregates to produce full volume slag alkali-activated mortars [18]. The results showed an improvement in the flowability and mechanical properties of the mortar with an increase in the replacement level of the ACBFS. In addition, ACBFS presence also increased the compactness of the microstructure, improving the permeability.

In work conducted by Sharma et al., the durability of self-compacting concrete (SCC) containing $\mathrm{Cu}$ slag as fine aggregate with a replacement level of $0 \%, 20 \%, 40 \%, 60 \%, 80 \%$, and $100 \%$ at a constant w/c ratio of 0.45 was studied [15]. The investigation suggested that $60 \%$ of $\mathrm{Cu}$ slag replacement was an ideal level of replacement for enhanced or comparable durability behavior to SCC possessing conventional aggregate. However, $100 \% \mathrm{Cu}$ slag as fine aggregate in the presence of FA and SF in SCC showed better performance in strength and absorption characteristics compared to a reference mix [14]. Moreover, the concrete having $100 \% \mathrm{Cu}$ slag as fine aggregate made with varying percentages of slags showed the lowest level of water absorption.

In addition, Chithra et al. investigated the effect of colloidal nano-silica on the properties of durability, such as rapid chloride penetration, water absorption, sorptivity, and abrasion resistance of high-performance concrete with $40 \% \mathrm{Cu}$ slag replacement as the fine aggregate. Cement was replaced by colloidal silica at $0.5 \%, 1 \%, 1.5 \%, 2 \%, 2.5 \%$ and $3 \%$, respectively [19]. The final observations stated that the resistance to chloride penetration, water absorption, and sorptivity was maximum when the $\mathrm{Cu}$ slag replacement as a fine aggregate was at $40 \%$, with $2 \%$ colloidal nano-silica replacement in the binder. Cu slag can also be used as fine aggregates in the hot-mix asphalt concrete [20]. The result indicated a compressive strength reduction as the $\mathrm{Cu}$ slag content increased within the mixes when compared to the reference mix (standard concrete), while 10\% replacement improved the indirect tensile strength.

Alnuaimi investigated the effect of $\mathrm{Cu}$ slag as a fine aggregate on the behavior and ultimate strength of the reinforced concrete beams [21]. The results showed that the replacement of up to $40 \%$ of the fine aggregate with $\mathrm{Cu}$ slag caused no major changes in the strength. However, further increase in the replacement levels reduced the concrete strength and flexural stiffness. The author stated that a reduction in the strength was due to an increased void content caused by the coarser particles and angular shape of the Cu slag as compared to the standard aggregate. Several authors also studied the effect of $\mathrm{Cu}$ slag as a fine aggregate on the concrete strength with FA and the GGBFS as partial Portland cement replacement [22-24]. The main finding again showed a decrease in the compressive and flexural strength for more than $50 \% \mathrm{Cu}$ slag replacement compared to the control mixture having standard aggregate (quartz). Shi et al. reviewed the characteristics of different copper slags. As an interesting discovery on the use of copper slag as a fine aggregate, the author stated that a wide range of research supports the use of $\mathrm{Cu}$ slag as a fine aggregate in concrete floors and pavements due to its reasonable hardness [25]. Moreover, the author stated that from an environmental point of view, the $\mathrm{Cu}$ slag can be considered as a safe material based on the criteria prescribed by different standards such as the United States Environmental Protection 
Agency and the United Nations based convention on the Transboundary Movement of Hazardous Wastes and their Disposal, which classifies Cu slags as "Non-hazardous wastes".

Analyzing a wide range of literature provides information that the usage of $\mathrm{Cu}$ slag as a fine aggregate improved the mechanical properties and also its durability in some cases. Furthermore, based on these studies, it could be deduced that an ideal replacement level tended to vary between $40 \%$ to $60 \%$. However, detailed knowledge on compressive strength related to the microstructure and morphology of this particular MFS slag aggregate is still missing. Moreover, due to the presence of a silica-rich amorphous phase, resistance toward alkali-silica reaction (ASR) and leaching are certain concerns that are noted while using the MFS slag as an aggregate. Alkali silica gel formation can absorb water and swell, causing internal stresses leading to the formation of cracks and causes further durability issues. Resistance toward ASR depends on certain factors such as 1) availability of the reactive silica in the system 2 ) alkalis in the pore solution 3) availability of water [26, 27]. Some literature also points out the importance of permeability of the mortar/concrete, where more permeable structures are more prone to the formation of the ASR gel $[28,29]$. The present work aims to completely replace the fine aggregate with processed $\mathrm{Cu}$ slag, further designated as the Modified Ferro Silicate (MFS) slag. These slags are similar to the Cu slags. However, the initial source of $\mathrm{Cu}$ is taken from $\mathrm{Cu}$ scrap instead of the $\mathrm{Cu}$ ore. The resistance toward alkali-silica reaction, carbonation, leaching behavior of the mortar containing $100 \%$ MFS slag aggregate along with the compressive strength and the microstructure and porosity were investigated.

\section{Materials and Methods}

\subsection{Cement and Aggregates}

The cement used in the study was Portland Cement (PC), supplied by Holcim (CEM I $52.5 \mathrm{~N}$ ). The CEN standard sand was used as the standard aggregate. As an alternative for the conventional standard aggregate, the patented Modified Ferro Silicate (MFS) slag (WO 2016156394 A1) was used.

\subsection{Specific Density, Water Absorption, Hardness and Sieve Analysis of Fine Aggregate (MFS Slag)}

The specific density and water absorption were determined as per the norm NBN EN 1097-6. Water absorption was determined after a soaking period of $24 \mathrm{~h}$ and was expressed as a percentage of the oven-dried mass of the aggregate sample. The hardness of the aggregates was expressed in the Mohs hardness scale and examined through the Mohs hardness standard method. NBN EN 9331 test method was used to determine the grading of the materials proposed for the utilization as aggregates. The results show the particle size distribution expressed in cumulative passing (\%) vs. particle size $(\mathrm{mm})$.

\subsection{X-Ray Fluorescence and X-Ray Diffraction}

Wavelength dispersive X-ray fluorescence spectrometry was used to determine the chemical composition of the proposed aggregate. The mineralogy of the MFS slag was determined by X-ray diffraction using 10 wt.\% internal standards (crystalline $\mathrm{Al}_{2} \mathrm{O}_{3}$ ). The internal standard was used for quantifying the diffractogram pattern using Rietveld analysis. An X-ray scan using $\mathrm{Cu} K$ alpha radiation with an acceleration voltage of $30 \mathrm{kV}$, a current of $30 \mathrm{~mA}$, a step size of $0.020^{\circ}$, and a 
counting time of $2.5 \mathrm{~s}$ per step was carried out. The diffraction pattern was obtained in a $2 \theta$-range from $8^{\circ}$ to $70^{\circ}$ and quantified with Topas academic V.5 software by using the Rietveld technique.

\subsection{Microstructural Analysis}

Microstructural analysis was carried out using Scanning Electron Microscopy (JSM 6510LV) on the polished MFS slag samples (Back Scattered Electron mode) and on the unpolished samples (Secondary Electron) of mortar having the MFS slag as an aggregate. Polished samples were prepared as follows: MFS slags were embedded in an epoxy resin, oil-polished and coated with a 5 nm layer of Pt.

\subsection{Leaching Analysis Through Column Test}

The aim of the column test (in accordance with NEN 7383) was to simulate the leaching of the inorganic components from the powder and the granulated material. The test was carried out in an aerobic environment, with a liquid (L)/Solid (S) value of 10 liters per kg of dry matter. The test determines the cumulative leaching. A sample having a specific particle size distribution $(95 \% \leq 4$ $\mathrm{mm}$ ) was placed into a vertical column ( $h=28 \mathrm{~cm}$ and $\mathrm{d}=10 \mathrm{~cm}$ ). Demineralized water was flown through the column for three weeks. Five eluate fractions were collected after three weeks and were immediately filtered, and the eluates were preserved. Later, these eluates were combined in proportions of the right volume for the chemical analysis using Inductively Coupled Plasma Atomic Emission Spectroscopy (ICP-AES). Similar leaching analyses through column tests for bottom ashes before and after the treatments can be found elsewhere [30].

\subsection{Mortar Preparation and Compressive Strength}

The test method described in the NBN EN 196-1 was used for determining the compressive strength of the prismatic mortar specimens having dimensions of $40 \mathrm{~mm} \times 40 \mathrm{~mm} \times 160 \mathrm{~mm}$. The samples were prepared by mechanical mixing and were compacted in a mold using a jolting apparatus as per the norm EN 196-1. The reference mortar contains one part by mass of cement, three parts by mass of CEN standard sand, and one-half part of water ( $w / c$ ratio 0.50 ), whereas the MFS mortar contains one part by mass of cement, three parts by mass of fine MFS slag and one-half part of water (Table 1). The prepared samples were cured at a temperature of $20^{\circ} \mathrm{C}$ with a relative humidity of $95 \%$ for $24 \mathrm{~h}$. Subsequently, the mortars were de-molded and stored in a curing chamber $\left(20^{\circ} \mathrm{C}\right.$ and $95 \%$ relative humidity) until the compressive strength was examined after 2,7 , 28 , and 90 days.

Table 1 Mortar composition in grams.

\begin{tabular}{lllll}
\hline Samples & water & Cement & Standard aggregate & MFS aggregate \\
\hline Reference & 225 & 450 & 1350 & 0 \\
MFS & 225 & 450 & 0 & 1350 \\
\hline
\end{tabular}




\subsection{Oberholster Test}

The Mortar specimens containing the MFS slag as fine aggregates and reference samples having standard aggregates ( 6 replicates) of dimensions $40 \mathrm{~mm} \times 40 \mathrm{~mm} \times 160 \mathrm{~mm}$ were prepared and demolded after 1 day, and was stored at a temperature of $20^{\circ} \mathrm{C}$ and $95 \%$ relative humidity for 28 days. After 28 days of curing, the mortars were tested with respect to their resistance to the alkali-silica reaction based on the South-African NBRI method or the Oberholster test. However, the sample size (test specimens were mortar bars instead of drilled cores), curing age, and the measurement days slightly deviated from the standard procedure. The MFS slag mortar and a reference sample (steel) were placed in a tank set up with a dial gauge installation, as shown in Figure 1 . The tank was filled with water and was maintained at a constant temperature of $80^{\circ} \mathrm{C}$. After $24 \mathrm{~h}$, the water in the tank was completely replaced by $1 \mathrm{M} \mathrm{NaOH}$ solution, and an initial reference measurement was carried out at $80^{\circ} \mathrm{C}$ after $1 \mathrm{~h}$. Expansion measurements of the MFS slag aggregate mortar were taken after $2,7,14,28,35,42,49,56$, and 63 days.
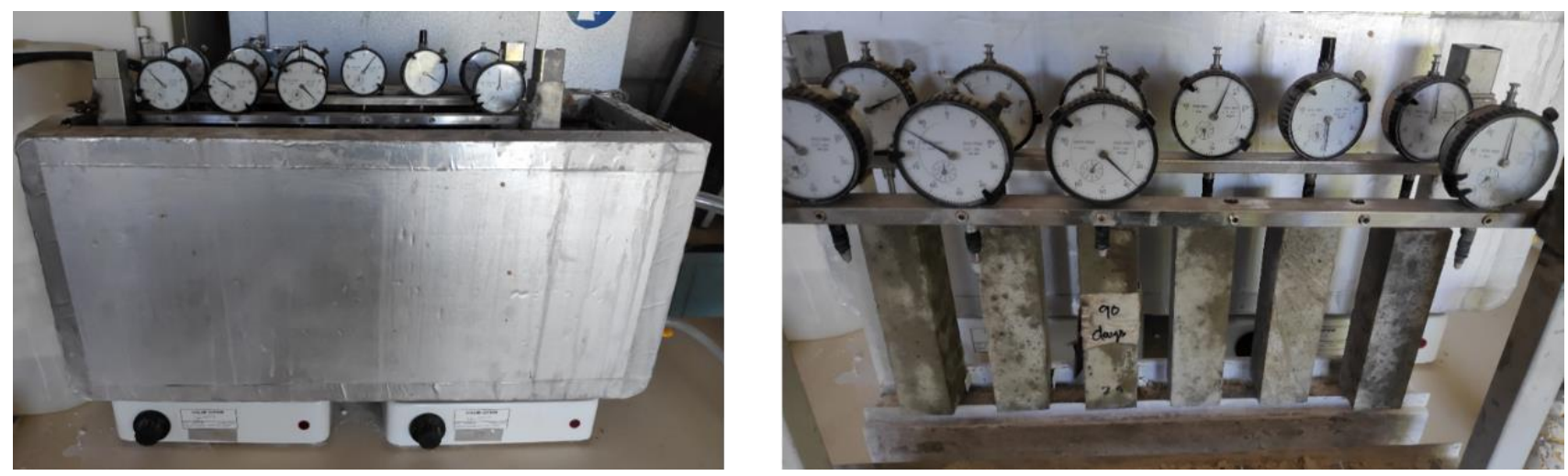

Figure 1 Oberholster set up to investigate the resistance to ASR.

\subsection{Mercury Intrusion Porosimetry (MIP)}

An automatic mercury porosimeter (Autopore IV 9500 series - Micromeritics) was employed to characterize the porosity of the mortar. The MIP measurements were carried out on crushed reference and the MFS slag mortars after curing for 1 year. The samples were placed in a container of a sealed penetrometer, which was connected to a capillary stem. The mass of the penetrometer was measured before being placed in a low-pressure port. The test chamber was then evacuated, and the penetrometer was filled with mercury. Later, the pressure was gradually increased, and the mercury intruded into the specimen, first into the largest pores. After intrusion at low pressure $(0$ to $200 \mathrm{kPa}$ ), the penetrometer was weighed again and was moved to the high-pressure chamber. The smaller pores were filled with mercury when the pressure increased up to $200 \mathrm{MPa}$. Finally, the mercury was partially extruded from the mortar sample in the high-pressure range from $200-0.1$ MPa. Two replicates per mortar mix were performed.

\subsection{Carbonation Test}

Three prisms having dimensions of $40 \mathrm{~mm} \times 40 \mathrm{~mm} \times 160 \mathrm{~mm}$ were made per mixture to investigate the carbonation resistance of the specimens. After demolding, the samples were stored 
and cured in a wet room at $20{ }^{\circ} \mathrm{C}$ and $>95 \% \mathrm{RH}$ for 28 days. Cured samples were further preconditioned for 14 days by placing them in an acclimatized room at $20{ }^{\circ} \mathrm{C}$ having $60 \%$ relative humidity. After the preconditioning, the specimens were stored in the controlled $\mathrm{CO}_{2}$ chamber with a concentration of $1 \% \mathrm{CO}_{2}$ at a temperature of $21 \pm 2{ }^{\circ} \mathrm{C}$ and relative humidity of $60 \pm 10 \%$ as prescribed in the norm EN 13925:2004. The depths of carbonation of the mortar were measured after $0,7,14,28$, and 91 days by spraying phenolphthalein on the split cross-section of the mortar. The solution of phenolphthalein indicator contained $1 \mathrm{~g}$ of phenolphthalein dissolved in $70 \mathrm{~mL}$ of ethanol, diluted to $100 \mathrm{~mL}$ of distilled water.

\section{Results}

\subsection{Specific Density, Water Absorption, Hardness and Sieve Analysis of Fine Aggregate (MFS Slag)}

Table 2 shows the mean values ( 3 repetitions) of specific density and water absorption of the MFS slag and the standard aggregate. The MFS slag has a specific density of $3.40 \mathrm{~g} / \mathrm{cm}^{3}$, whereas the standard aggregate possesses a density of $2.77 \mathrm{~g} / \mathrm{cm}^{3}$. Therefore, due to a higher density of the MFS slag, the mortar produced shall possess a higher density than the reference mortar. Moreover, the water absorption for the MFS slag was $0.4 \%$, but meanwhile, $1.1 \%$ for the standard aggregate. These results suggest that the MFS aggregate in the mortar would absorb less water compared to the standard aggregate. Figure 2 shows the sieve analysis of the MFS slag and the standard aggregate. It is seen that the MFS slag shows a similar range of grading as the standard aggregate; however, it is somewhat coarser.

Table 2 Specific density, water absorption and hardness.

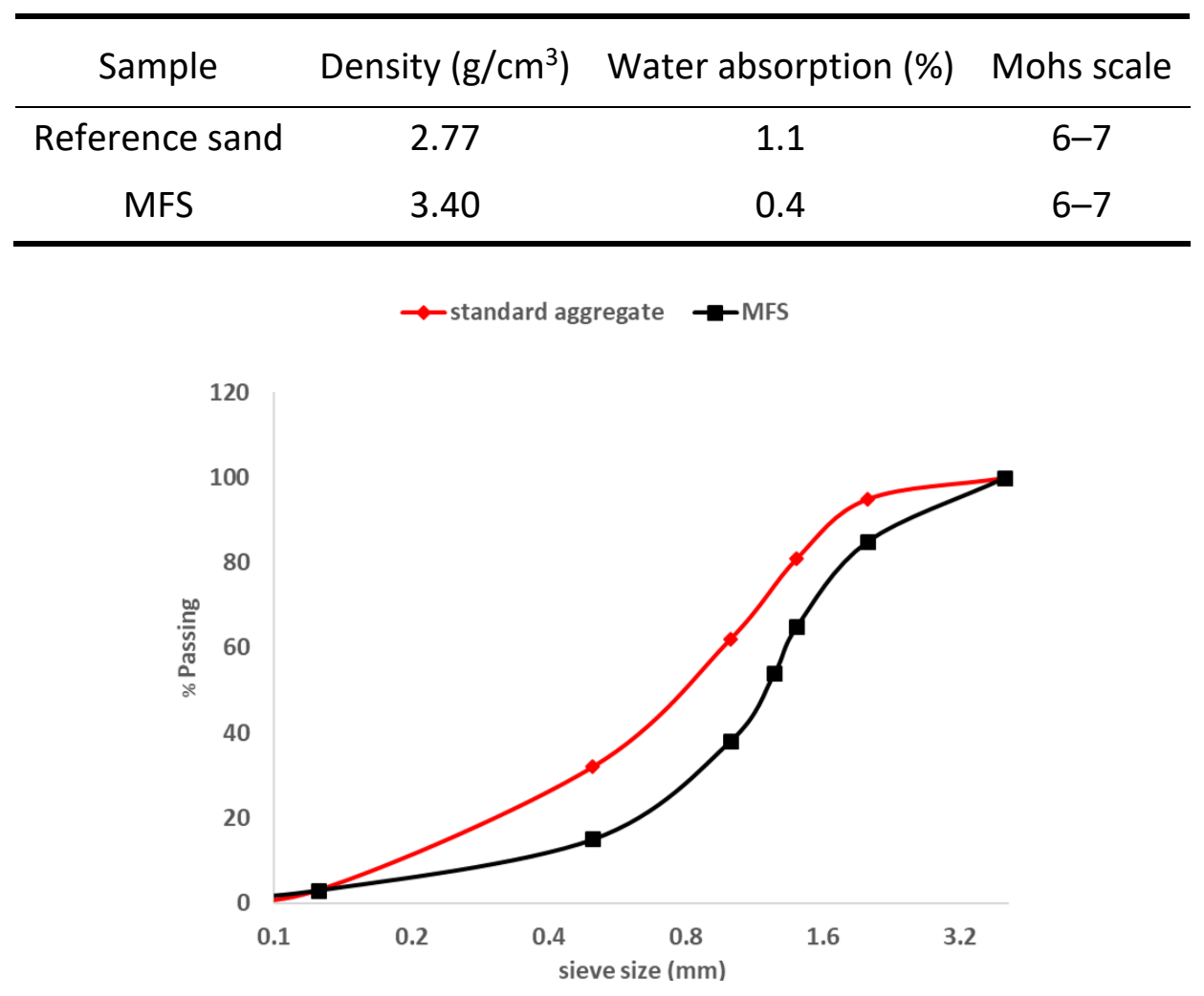

Figure 2 Sieve analysis (\% passing vs. sieve size at logarithmic scale). 


\subsection{X-Ray Fluorescence and X-Ray Diffraction}

Table 3 presents the measured chemical compositions of the cement, the standard aggregate, and the MFS slag through X-ray fluorescence. The MFS slag mainly contains oxides of $\mathrm{Fe}$ and $\mathrm{Si}$, whereas the standard aggregates only have $\mathrm{SiO}_{2}$. The CEM I $52.5 \mathrm{~N}$ contains significant components such as $\mathrm{CaO}$ and $\mathrm{SiO}_{2}$ and minor components such as $\mathrm{Fe}_{2} \mathrm{O}_{3}$ and $\mathrm{Al}_{2} \mathrm{O}_{3}$. The MFS slag mainly possesses a glassy structure due to the pyro-metallurgy process followed by quick water quenching. It also contains minor crystalline phases such as spinel and metallic iron (Table 4).

Table 3 Chemical composition of raw materials in wt\%.

\begin{tabular}{cccccc}
\hline Component & $\left(\mathrm{FeO}+\mathrm{Fe}_{2} \mathrm{O}_{3}\right)$ & $\mathrm{SiO}_{2}$ & $\mathrm{Al}_{2} \mathrm{O}_{3}$ & $\mathrm{CaO}$ & Others \\
\hline MFS & 40.9 & 32.3 & 11.0 & 3.9 & 11.9 \\
Standard aggregate & - & 97 & - & - & 3 \\
Cement & 3.5 & 20.8 & 4.7 & 63.0 & 8 \\
\hline
\end{tabular}

Table 4 Mineralogy of MFS and standard aggregates in wt\%.

\begin{tabular}{cccccc}
\hline Component & Amorphous & Spinel & Iron & Quartz & Others \\
\hline MFS & 92.7 & 6.7 & 0.6 & 0 & 0 \\
Standard aggregate & 2.5 & 0 & 0 & 97.5 & 0 \\
\hline
\end{tabular}

\subsection{Microstructural Analysis}

Figure 3a shows the backscattered image of the MFS, which is mainly composed of non-porous tiny angular crystals. Microstructural investigation revealed that these crystals contain a multiphase structure. By interpreting the microstructural analysis with XRD results, we can state that the MFS slag mainly possesses amorphous phases and trace amounts of crystalline spinel phases (Figure $3 \mathrm{~b}$ ). The rapid quenching of the liquid slag explains the presence of the amorphous phase with water. As expected, the composition of the amorphous phase was rich in oxides of Fe and Si (Table 5). The composition of the spinel phase determined by the EDX point analysis showed that it consisted of $\mathrm{Mg}, \mathrm{Zn}, \mathrm{Fe}$, and $\mathrm{Al}$ in oxides form.

Table 5 Composition of the MFS slag amorphous phase.

\begin{tabular}{cccccc}
\hline Component & $\mathrm{FeO}$ & $\mathrm{SiO}_{2}$ & $\mathrm{Al}_{2} \mathrm{O}_{3}$ & $\mathrm{CaO}$ & others \\
\hline wt\% & $41.2 \pm 2.6$ & $29.8 \pm 2.6$ & $9.5 \pm 2.6$ & $6.2 \pm 2.6$ & $13.3 \pm 2.6$ \\
\hline
\end{tabular}


a)

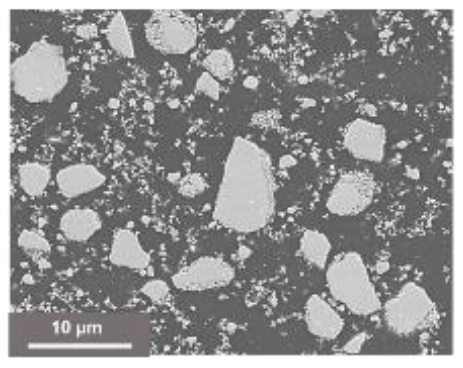

b)

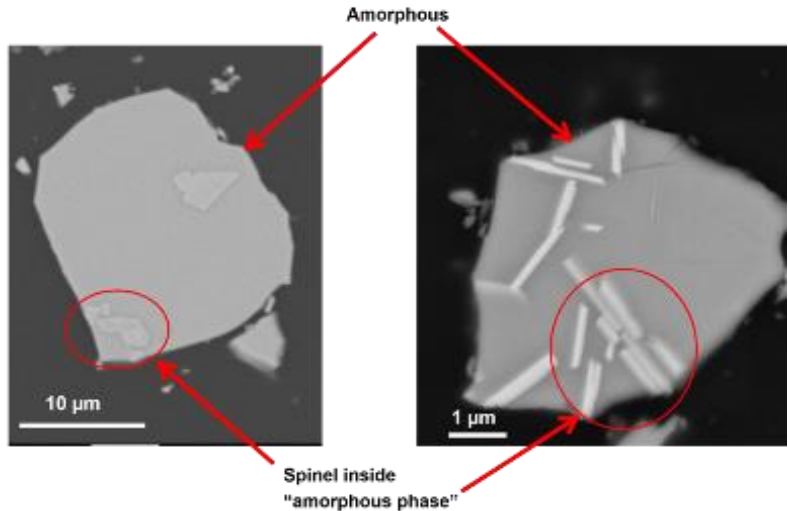

Figure 3 BSE image of MFS: a) an overview of the MFS slag; b) amorphous grain of the MFS slag.

\subsection{Leaching Analysis Through Column Test}

Heavy metals in the slag are prone to leaching due to chemical and physical processes [31]. However, the $\mathrm{pH}$ and oxidation state of elements are essential parameters that control the leaching behavior. For instance, Zhang et al. showed that the oxidation state might be a vital factor in maintaining the leaching behavior of $\mathrm{Cr}$ [32]. Since this project is executed in Flanders, Belgium, certain limits prescribed by the government (VLAREMA 4) must be satisfied by the aggregates before being used in the construction application. Table 6 shows the leaching behavior of the MFS slag through the column test and compares it to the maximum allowed limit. All elements showed leaching values well below the limit prescribed by the legislation policy due to the possible encapsulation of heavy metals in the spinel phases [33]. Thus, MFS slag potentially is a safe alternative replacement for standard aggregate. 
Table 6 Leaching from MFS slag (5 replicates) with maximum allowed limit.

\begin{tabular}{lllllll}
\hline & \multicolumn{7}{l}{ Cumulative column test release for L/S = 10 (mg/kg) } & & \\
Parameters & Batch 1 & Batch 2 & Batch 3 & Batch 4 & Batch 5 & Limit \\
\hline Antimony (Sb) & 0.038 & 0.023 & 0.022 & 0.021 & 0.056 & $\mathbf{1}$ \\
Arsenic (As) & 0.068 & $<0.050$ & $<0.050$ & $<0.050$ & $<0.050$ & $\mathbf{0 . 8}$ \\
Barium (Ba) & $<0.60$ & $<0.60$ & $<0.60$ & $<0.60$ & $<0.60$ & $\mathbf{2 0}$ \\
Cadmium (Cd) & $<0.00100$ & 0.0017 & $<0.00100$ & $<0.00100$ & 0.0019 & $\mathbf{0 . 0 3}$ \\
Chromium (Cr) & $<0.100$ & $<0.100$ & $<0.100$ & $<0.100$ & $<0.100$ & $\mathbf{2 . 6}$ \\
Copper (Cu) & $<0.050$ & $<0.050$ & $<0.050$ & $<0.050$ & $<0.050$ & $\mathbf{0 . 8}$ \\
Mercury (Hg) & $<0.00040$ & $<0.00040$ & $<0.00040$ & $<0.00040$ & $<0.00040$ & $\mathbf{0 . 0 2}$ \\
Lead (Pb) & $<0.100$ & $<0.100$ & $<0.100$ & $<0.100$ & $<0.100$ & $\mathbf{1 . 3}$ \\
Nickel (Ni) & $<0.050$ & $<0.050$ & $<0.050$ & $<0.050$ & $<0.050$ & $\mathbf{0 . 7 5}$ \\
Selenium (Se) & 0.013 & 0.009 & 0.013 & 0.013 & 0.014 & $\mathbf{2}$ \\
Tin (Sn) & $<0.020$ & $<0.020$ & $<0.020$ & $<0.020$ & $<0.020$ & $\mathbf{1}$ \\
Vanadium (V) & $<0.20$ & $<0.20$ & $<0.20$ & $<0.20$ & $<0.20$ & $\mathbf{2 . 5}$ \\
Zinc (Zn) & $<0.20$ & $<0.20$ & 0.26 & $<0.20$ & 0.22 & $\mathbf{2 . 8}$ \\
\hline
\end{tabular}

\subsection{Compressive Strength}

An assessment of the compressive strength was carried out for the mortars containing a standard aggregate and the MFS slag (Figure 4). Moreover, a statistical analysis was carried out to check whether the compressive strength of the MFS slag mortar showed a significant difference relative to the standard mortar or not.

The 2-days compressive strength of the MFS slag mortar showed relatively similar values (around $43 \mathrm{MPa}$ ), whereas the 7-days strength showed slightly lower values compared to the standard aggregate mortar. This increase in strength could be due to the higher density of the MFS slag than the standard aggregate. At 28 and 90 days, the MFS slag mortar showed higher compressive strength (70 MPa at 28 days and $78 \mathrm{MPa}$ at 90 days) relative to the standard aggregate mortar (66 $\mathrm{MPa}$ at 28 days and $75 \mathrm{MPa}$ at 90 days). It can also be proposed that finer particles of the MFS slag potentially reacted and formed binders due to pozzolanic reaction at later ages [9].

A t-test (significance level 0.05) of the compressive strength of the MFS slag mortar after 2, 7, 28, and 90 days relative to the compressive strength of the standard mortar indicated a significant difference in the strength only at the later ages of 28 and 90 days. This statistic supports the possible claim of the reactivity of fine particles and the contribution to the binding phases; thus, forming a dense microstructure. 


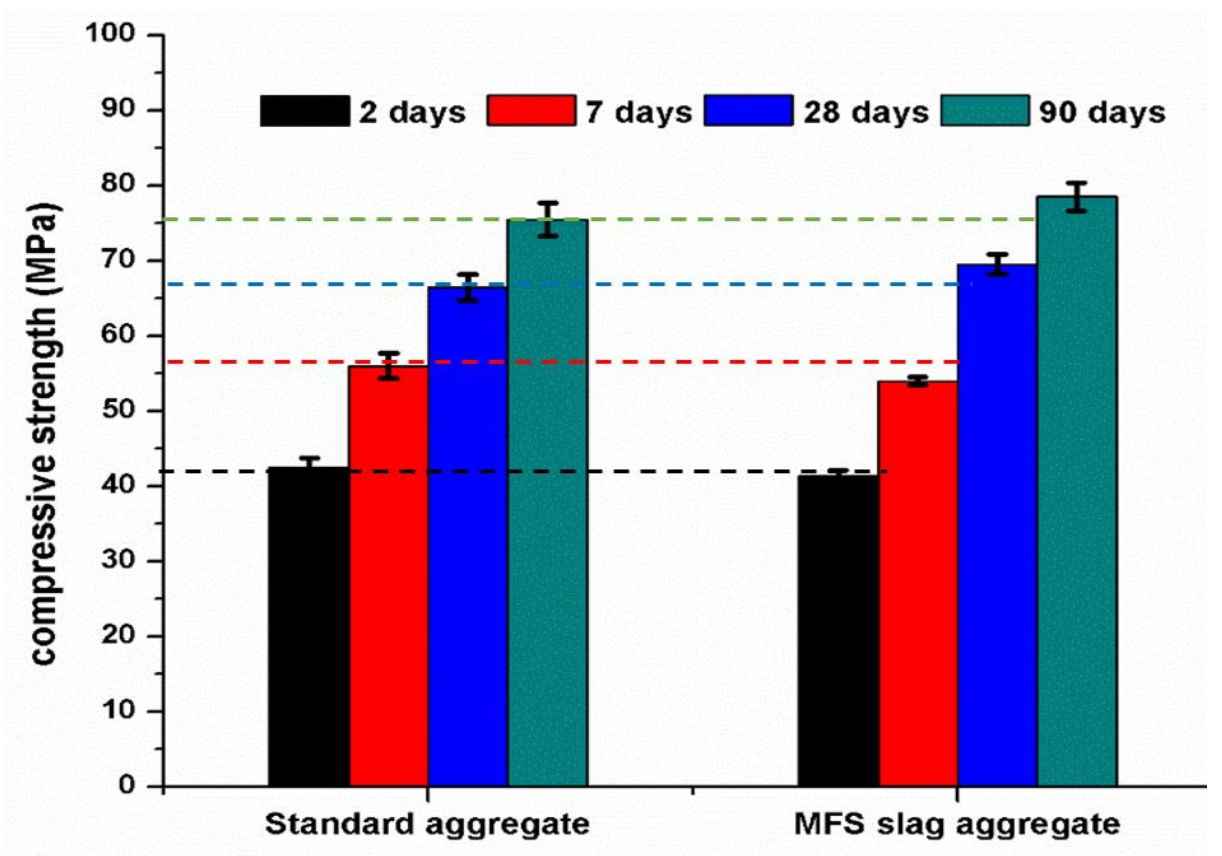

Figure 4 Compressive strength of the mortar with a standard sand and MFS slag.

\subsection{Microstructural Investigation and Elemental Mapping}

A microstructural investigation was carried out on the mortar containing MFS slag as an aggregate after a curing period of 1 year. The experiment was performed on unpolished samples to see the morphology of the binder and to obtain information on the ITZ. Figure 5 shows a secondary electron (SE) image of the mortar containing the MFS slag as aggregate, where the interfacial transition zone (ITZ) divides the aggregate and binder.
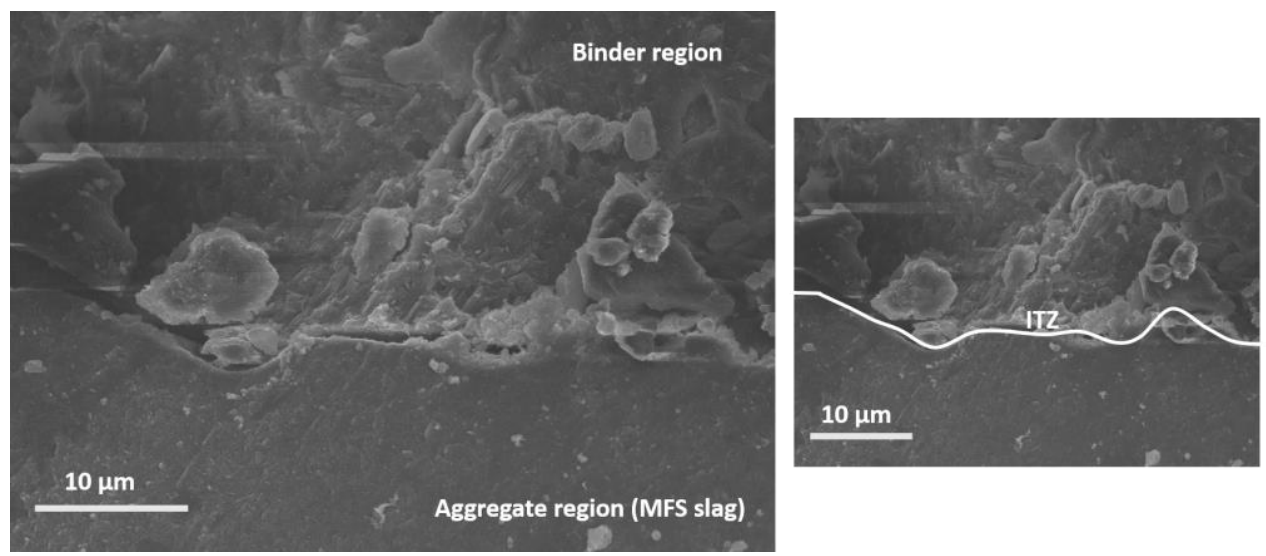

Figure 5 Microstructural analysis of binder, aggregate, and ITZ in the MFS slag mortar after one year.

The ITZ is a transition zone, and its effective "width" depends upon the used aggregate and the reaction degree of the binder [34-36]. Figure 6 shows a typical ITZ in an MFS slag mortar. Firstly, to determine the width of the ITZ, the boundary of aggregates needs to be defined. From Figure 5, it can be stated that the microstructure of the cement paste was dense. The images in Figure 6 were mainly captured in and around the MFS slag mortar interface, where the MFS slag mortar interface 
mainly contained loose granular C-S-H and ettringite crystals. As a result, the ITZ of the MFS slag mortar was porous compared with that of the standard aggregate mortar (Figure 7). The following reasons can be stated for the more porous ITZ in the MFS slag mortar: (1) the shape of the MFS slag particles was more angular and irregular compared to that of natural sand; (2) MFS slag was more rigid compared to natural sand; similar results were also reported elsewhere regarding the presence of harder grains (mainly aggregates) which lead to porous ITZ; (3) water absorption of the MFS slag is relatively low compared to the natural sand, which leads to increased local w/c factor [37]. Due to the more porous ITZ, the porosity of the MFS slag mortar as a whole was higher compared to the standard aggregate mortar, as also explained in Section 3.8. Figure 7 illustrates the denser ITZ of the standard aggregate mortars; large pores between cement paste and aggregates are hardly seen.

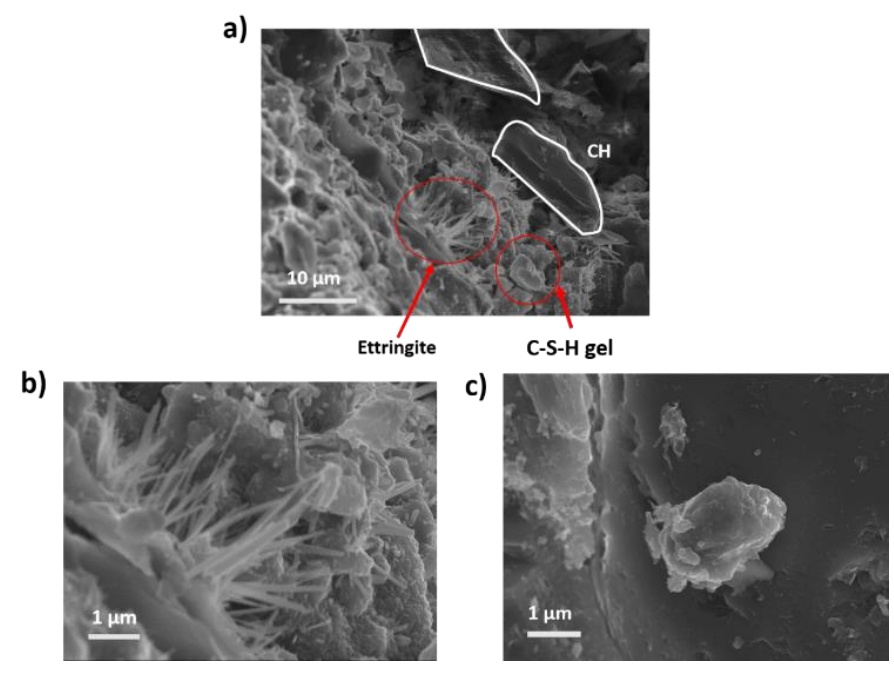

Figure 6 Microstructural analysis around the interface in the MFS slag mortar after one year: a) binder region, b) ettringite needles, c) C-S-H gel.

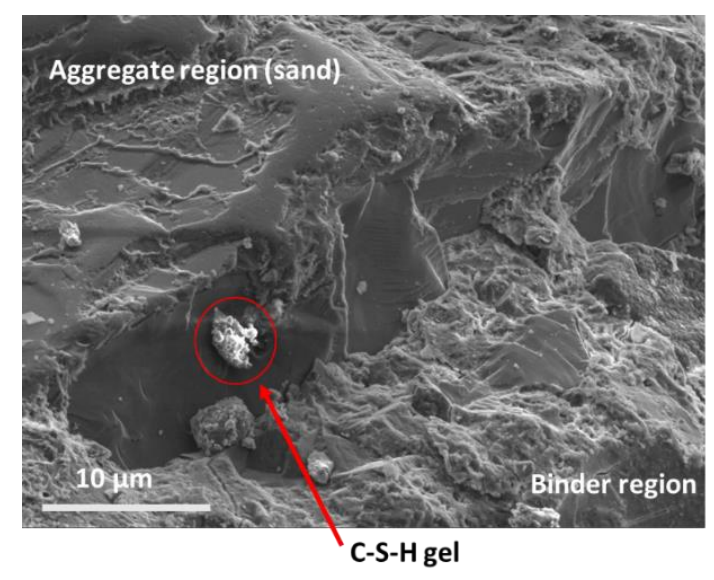

Figure 7 Microstructural analysis of the ITZ in the standard aggregate mortar after one year.

\subsection{Mercury Intrusion Porosimetry}

The Mercury intrusion measurements were performed on the standard and the MFS slag mortar at one year. Figure 8 shows the results of the pore size distribution, where the capillary and gel 
pores can be found in the densely packed PC binder mortars [38]. During hydration of the PC binder, capillary pores are formed due to the formation of the hydration product. The total capillary porosity consists of the capillary pores and capillary water in the first stage of hydration. However, the gel pores are present in the C-S-H phase itself. Therefore, the volume of the capillary pores decreases while the volume of the gel pore increases during later ages [39-41]. Typically, capillary pores and the corresponding capillary porosity are present in the range of $0.01 \mu \mathrm{m}<\mathrm{D}<10 \mu \mathrm{m}$ [38].

In contrast, the gel pores can be present in the range $D<0.01 \mu \mathrm{m}[42]$. As seen in Figure 9, there is a massive peak at $0.7 \mu \mathrm{m}$, around the proposed region of capillary porosity for the MFS mortar. Thus, the MFS slag aggregate in the PC binder increases the capillary porosity compared to the standard aggregate. Moreover, the MFS slag mortar also showed increased porosity in the gel pores region. The following factors can be considered for the increased porosity: 1) the MFS slag mortar contains more paste in general (because the density of standard sand and MFS slag are different); thus, more C-S-H binder leads to an increase of gel pores, 2) C-S-H can also be formed due to the pozzolanic reaction of more refined MFS slag grains. As a result, the standard and MFS slag mortar showed a total porosity of $4.9 \%$ and $6.1 \%$, respectively. These porosity values can be considered relatively low, but it is related to the pore refinement at later ages ( 1 year). Similar results were also mentioned in the work of Pandey et al., where the PC binder mortar at later ages ( 90 days) showed total porosity less than $7 \%$ due to its finer microstructure [43].

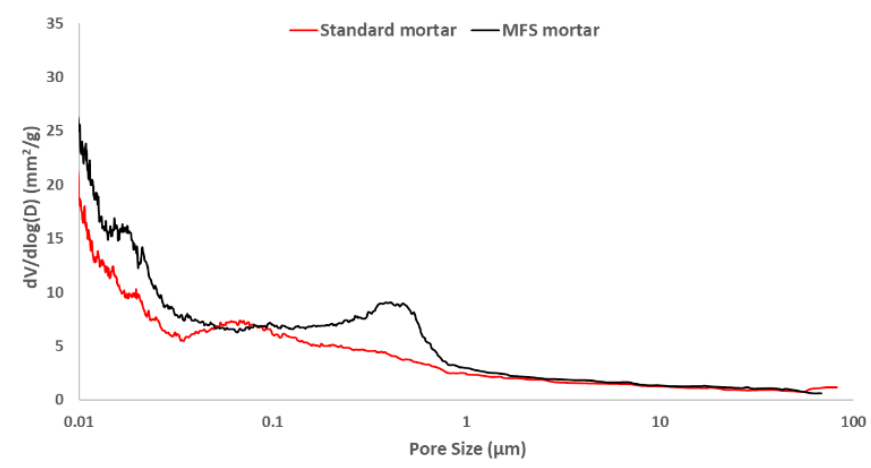

Figure 8 Pore size distribution, MFS slag mortar, and standard mortar after one year.

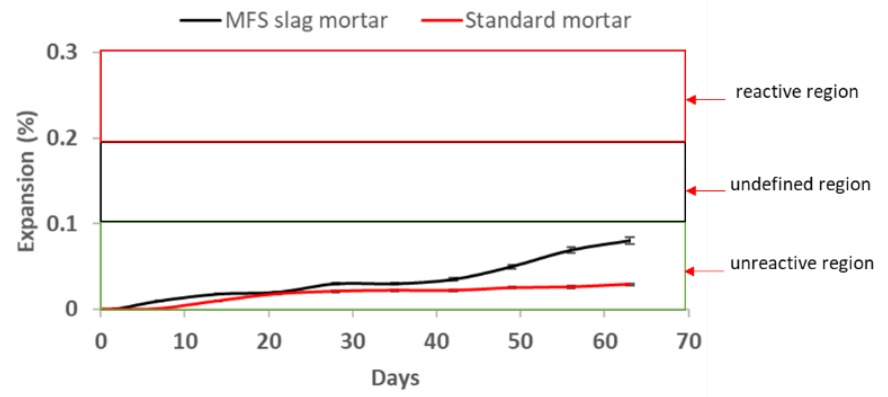

Figure 9 Expansion vs. time for MFS slag \& standard mortars (1 M NaOH solution at $80^{\circ}$ C).

\subsection{Resistance to the Alkali-Silica Reaction (ASR)}

Figure 9 shows an expansion in mortars' function with the MFS slag aggregate exposed to the Oberholster test. Based on the literature, there are two limit values giving the boundaries between 
three zones: 1 ) $<0.1 \%$ : unreactive region, 2 ) $0.1-0.2 \%$ : undefined region, 3 ) $>0.2 \%$ reactive region [44]. However, these limits are for samples cured for two days during an exposure period of 28 days. From literature and experience, it was seen that the older samples subjected to the Oberholster test showed a higher expansion rate [45-47]. Several authors have speculated that the samples at an earlier age possess an open pore structure, which provides space for the swelling of the alkalisilica gel; thus, showing no/undetectable expansion in the dial gauges [48-50]. However, gel in the dense microstructure at a later age creates high swelling pressures, leading to higher expansion. For this reason, the MFS slag and standard mortars were cured for 28 days aiming for a dense microstructure, and were then subjected to the Oberholster test to monitor their expansion.

The expansion of the MFS slag mortar is seen to be higher than the standard mortar. However, it still fits in the unreactive region and thus can be considered as a safe aggregate. A possible reason for this could be the presence of a high amount of $\mathrm{FeO}$ in the glass phase. A wide range of authors also reported that the mortars with $\mathrm{Cu}$ slag aggregates showed limited expansion [51-53]. However, it is also noticed that the reason behind the limited expansion was not explicitly mentioned in these studies. It can be hypothetically stated that the reactive silica present in the amorphous phase is surrounded by the $\mathrm{FeO}$ and spinel phase (Figure 3); thus, preventing the dissolution and reaction toward ASR. Moreover, the high density of the MFS slag and lower water absorption are also vital factors preventing the ASR reaction in the MFS slag aggregate.

\subsection{Resistance to the Carbonation}

Figure 10 shows the carbonation depth of the MFS slag mortar and standard aggregate mortar after exposure for $0,7,28,56$, and 91 days to an environment with $1 \% \mathrm{CO}_{2}$. By comparing the MFS slag and the standard aggregate mortar's carbonation depth, the MFS slag mortar showed increased carbonation depth. Since both mortars contain Portland cement as a binder, the addition of MFS slag as an aggregate decreases the carbonation resistance of the cement matrix. The lower carbonation resistance for the MFS slag mortar can be related to the possible pozzolanic reaction and increased porosity in the MFS slag mortar compared to the standard aggregate mortar, as explained in Sections 3.5 and 3.8. In addition, the replacement of standard sand by the MFS slag is carried out by mass. Due to the higher density, the MFS mortar has a lower fraction of aggregates in volume and, therefore, has relatively more binder. In the exciting work conducted, the effects of the binder content on the carbonation depth were studied. It is stated that increasing the amount of the binder (exceeding $400 \mathrm{~kg} / \mathrm{m}^{3}$ ) also increases the carbonation depth [54]. Moreover, in a recently made detailed review study, it was also stated that the carbonation tests conducted in the case of mortars could only give an indication of concrete performance and that usually, the carbonation coefficients of mortar can be higher by a factor of 1.2-2.3, respectively (depending on the binder type and $\mathrm{CO}_{2}$ concentration), compared to the carbonation coefficients of concrete [55]. Thus, the carbonation effect of the MFS slag while applied in the concrete system can be considered relatively low. 


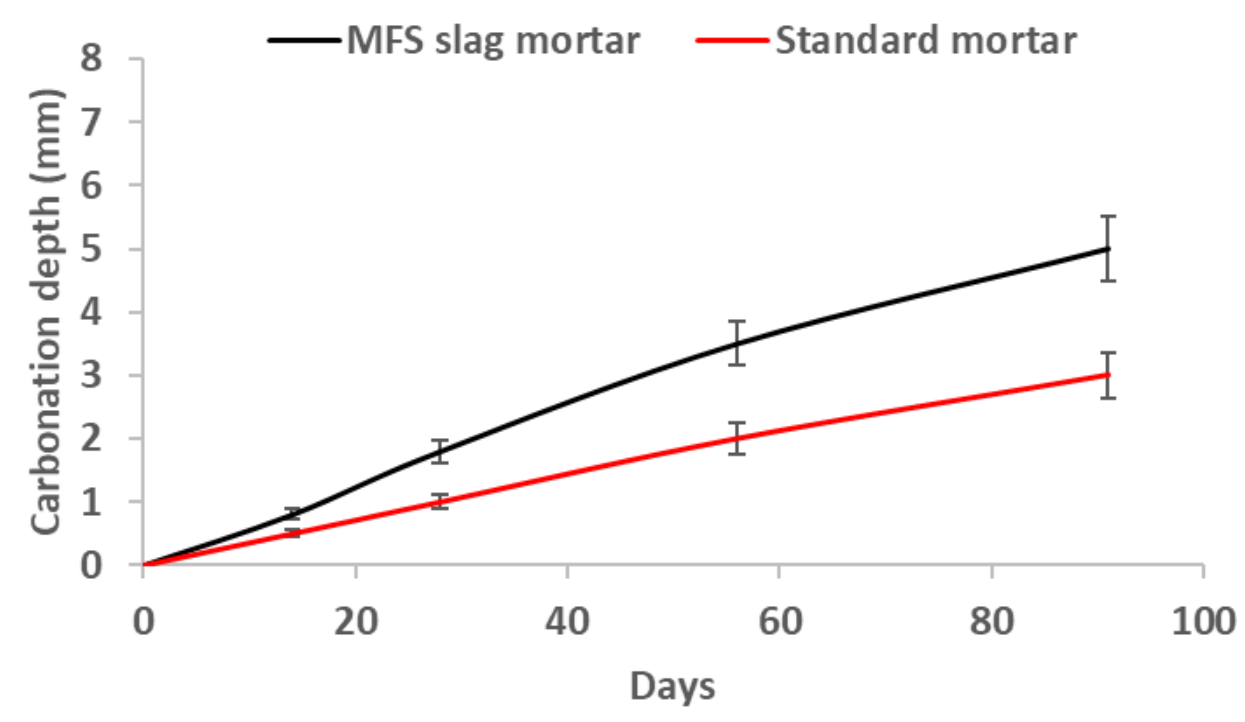

Figure 10 Carbonation depth at $1 \% \mathrm{CO}_{2}$ conc.

\section{Conclusions}

The present work showed that the currently studied MFS slag could replace standard sand in mortar. Using MFS slag as aggregate serves many sustainability goals and has some vital advantages, such as; (1) reduction in energy consumption, (2) preserving natural resources from depletion, (3) maintaining ecological balance, and (4) reduction in the cost of concrete.

The following can be stated as the essential findings of the current feasibility study on the use of modified copper slag as a sustainable fine aggregate in mortar:

1) Due to its high specific density and hardness, mortar synthesized with MFS slag showed good mechanical properties. Further microstructural analysis showed that the amorphous phase was rich in oxides of $\mathrm{Fe}$ and $\mathrm{Si}$. Due to the presence of $\mathrm{FeO}$ in the amorphous phase, the MFS slag aggregate mortar showed good resistance toward the ASR reaction according to the Oberholster test, and It could be considered an unreactive aggregate. However, further experiments such as selective dissolution on the slag must be carried out to understand the amorphous phase's dissolution better.

2) A column test showed limited leaching for the MFS slag. All elements showed leaching values well below the limit suggested by the legislation policy. Therefore, this MFS slag is seen as a sustainable source of alternative aggregate by the construction companies since there are no additional processing needs.

3) The application of the MFS slag in mortar resulted in an adverse effect on the carbonation resistance. However, the product can still be considered reasonably low. The MFS slag and standard aggregate mortar showed a $5 \mathrm{~mm}$ and $3 \mathrm{~mm}$ carbonation depth, respectively, after 91 days at $1 \%$ $\mathrm{CO}_{2}$ concentration.

\section{Acknowledgments}

The authors are grateful to Metallo Belgium for providing the MFS slag, and Mr Lars Cuyvers from Metallo Belgium for helping us with the leaching test. The author would like to thank SIM for funding the DUSC project within the MARES program. MARES aims at creating and demonstrating an 
operational, flexible toolbox to recover metals and valorize the residual matrix into building materials. The research has been carried out in the Magnel-Vandepitte Laboratory for Structural Engineering, and Building Materials, Ghent University, and the authors want to thank the technical and administrative staff for their help.

\section{Additional Materials}

The data presented in this study are available on request from the corresponding author. The data are not publicly available due to the SIM ICON Project Agreement DUSC (HBC.2017.0607), Contract ref. A18TT1346.

\section{Author Contributions}

Conceptualization: N.D.B., S.M., E.G., P.P.S.; methodology: P.P.S., N.D.B., S.M., E.G.; formal analysis and investigation: P.P.S.; writing-original draft preparation: P.P.S.; writing-review and editing: N.D.B., S.M., E.G.; funding acquisition: S.M., N.D.B., E.G.; resources: N.D.B., S.M.; supervision: S.M., N.D.B., E.G. All authors have read and agreed to the published version of the manuscript.

\section{Funding}

This research was funded by the SIM MARES program (DUSC project), grant number HBC.2017.0607

\section{Competing Interests}

The authors have declared that no competing interests exist.

\section{References}

1. Turk J, Cotič Z, Mladenovič A, Šajna A. Environmental evaluation of green concretes versus conventional concrete by means of LCA.Waste Manag. 2015; 45: 194-205.

2. Faleschini F, Zanini MA, Pellegrino C, Pasinato S. Sustainable management and supply of natural and recycled aggregates in a medium-size integrated plant. Waste Manag. 2016; 49: 146-155.

3. Schlesinger ME, Sole KC, Davenport WG. Extractive metallurgy of copper. 5th ed. Amsterdam, Netherlands: Elsevier; 2011.

4. Davenport WG, King MJ, Schlesinger ME, Biswas AK. Extractive metallurgy of copper. Amsterdam, Netherlands: Elsevier; 2002.

5. Hagelüken C. Recycling of electronic scrap at Umicore. Precious metals refining. Acta Metall Slovaca. 2006; 12: 111-120.

6. Chew SH, Bharati SK. Use of recycled copper slag in cement-treated singapore marine clay. In: Advances in environmental geotechnics. Berlin, Heidelberg: Springer; 2011.

7. Bharati SK, Chew SH. Geotechnical behavior of recycled copper slag-cement-treated singapore marine clay. Geotech Geol Eng. 2016; 34: 835-845.

8. Gorai B, Jana RK. Characteristics and utilisation of copper slag-A review. Resour Conserv Recycl. 2003; 39: 299-313. 
9. Sivakumar PP, Gruyaert E, De Belie N, Matthys S. Reactivity of modified iron silicate slag as sustainable alternative binder. Proceedings of the 5 th International Conference on Sustainable Construction Materials and Technologies; 2019 July 14; London, England. DOI: 10.18552/2019/IDSCMT5134.

10. Al-Jabri KS, Hisada M, Al-Saidy AH, Al-Oraimi SK. Performance of high strength concrete made with copper slag as a fine aggregate. Constr Build Mater. 2009; 23: 2132-2140.

11. Wu W, Zhang WD, Ma GW. Optimum content of copper slag as a fine aggregate in high strength concrete. Mater Des. 2010; 31: 2878-2883.

12. Ishimaru K, Mizuguchi H, Hashimoto C, Ueda T, Fujita K, Ohmi M. Properties of concrete using copper slag and second class fly ash as a part of fine aggregate. Zair Soc Mater Sci Japan. 2005; 54: 828-833.

13. Al-Jabri KS, Al-Saidy AH, Taha R. Effect of copper slag as a fine aggregate on the properties of cement mortars and concrete. Constr Build Mater. 2011; 25: 933-938.

14. Sharma R, Khan RA. Sustainable use of copper slag in self compacting concrete containing supplementary cementitious materials. J Clean Prod. 2017; 151: 179-192.

15. Sharma R, Khan RA. Durability assessment of self compacting concrete incorporating copper slag as fine aggregates. Constr Build Mater. 2017; 155: 617-629.

16. Al-Jabri KS, Hisada M, Al-Oraimi SK, Al-Saidy AH. Copper slag as sand replacement for high performance concrete. Cem Concr Compos. 2009; 31: 483-488.

17. Wu W, Zhang WD, Ma GW. Mechanical properties of copper slag reinforced concrete under dynamic compression. Constr Build Mater. 2010; 24: 910-917.

18. Shi JY, Tan JX, Liu BJ, Chen JZ, Dai JD, He ZH. Experimental study on full-volume slag alkaliactivated mortars: Air-cooled blast furnace slag versus machine-made sand as fine aggregates. J Hazard Mater. 2021; 403: 123983.

19. Chithra S, Senthil Kumar SR, Chinnaraju K. The effect of colloidal nano-silica on workability, mechanical and durability properties of high performance concrete with copper slag as partial fine aggregate. Constr Build Mater. 2016; 113: 794-804.

20. Hassan HF, Al-Jabri K. Laboratory evaluation of hot-mix asphalt concrete containing copper slag aggregate. J Mater Civ Eng. 2011; 23: 879-885.

21. Alnuaimi AS. Effects of copper slag as a replacement for fine aggregate on the behavior and ultimate strength of reinforced concrete slender columns. J Eng Res. 2012; 9: 90-102.

22. Dash MK, Patro SK, Rath AK. Sustainable use of industrial-waste as partial replacement of fine aggregate for preparation of concrete - A review. Int J Sustain Built Environ. 2016; 5: 484-516.

23. Velumani M, Nirmalkumar K. Durability and characteristics of copper slag as fine aggregate and fly ash as cement in concrete. Proceedings of the 2nd International Conference on Current Trends In Engineering and Technology; 2014 July 8; Coimbatore, India. New York: Institute of Electrical and Electronics Engineers.

24. Pavan Kumar M, Mahesh Y. The behaviour of concrete by partial replacement of fine aggregate with copper slag and cement with GGBS - an experimental study. Int Res J Eng Technol. 2017; 12: 51-56.

25. Shi CJ, Meyer C, Behnood A. Utilization of copper slag in cement and concrete. Resour Conserv Recycl. 2008; 52: 1115-1120.

26. Chatterji S, Thaulow N, Jensen AD. Studies of alkali-silica reaction, part 6 . Practical implications of a proposed reaction mechanism. Cem Concr Res. 1988; 18: 363-366. 
27. Fernández-Jiménez $A$, Puertas $F$. The alkali-silica reaction in alkali-activated granulated slag mortars with reactive aggregate. Cem Concr Res. 2002; 32: 1019-1024.

28. Drolet C, Duchesne J, Fournier B. Effect of alkali release by aggregates on alkali-silica reaction. Constr Build Mater. 2017; 157: 263-276.

29. Shi ZG, Shi CJ, Zhang J, Wan S, Zhang ZH, Ou ZH. Alkali-silica reaction in waterglass-activated slag mortars incorporating fly ash and metakaolin. Cem Concr Res. 2018; 108: 10-19.

30. Tang P, Florea MV, Spiesz P, Brouwers HJ. Application of thermally activated municipal solid waste incineration (MSWI) bottom ash fines as binder substitute. Cem Concr Compos. 2016; 70; 194-205.

31. van der Sloot HA, Dijkstra JJ. Development of horizontally standardized leaching tests for construction materials: A material leaching mechanisms for different materials ? Identical leaching mechanisms for different materials [Internet]. Energy research Centre of the Netherlands; 2004. Available from: https://www.osti.gov/etdeweb/biblio/20517922.

32. Zhang JG, Provis JL, Feng DW, van Deventer JS. Geopolymers for immobilization of $\mathrm{Cr}^{6+}, \mathrm{Cd}^{2+}$, and $\mathrm{Pb}^{2+}$. J Hazard Mater. 2008; 157: 587-598.

33. Guo B, Liu B, Yang J, Zhang SG. The mechanisms of heavy metal immobilization by cementitious material treatments and thermal treatments: A review. J Environ Manage. 2017; 193: 410-422.

34. Zhang JJ, Zhang $\mathrm{L}$, Sun GW, Wang $\mathrm{CH}$. Modeling and software development of the interfacial transition zone of ellipsoidal aggregate in cement-based composites. J Wuhan Univ Technol Mater. 2019; 34: 648-655.

35. Sun GW, Sun W, Zhang YS, Liu ZY. Numerical calculation and influencing factors of the volume fraction of interfacial transition zone in concrete. Sci China Technol Sci. 2012; 55: 1515-1522.

36. Lyu K, She W, Chang HL, Gu Y. Effect of fine aggregate size on the overlapping of interfacial transition zone (ITZ) in mortars. Constr Build Mater. 2020; 248: 118559.

37. Brand AS, Roesler JR. Bonding in cementitious materials with asphalt-coated particles: Part Ithe interfacial transition zone. Constr Build Mater. 2017; 130: 171-181.

38. Diamond S. Aspects of concrete porosity revisited. Cem Concr Res. 1999; 29: 1181-1188.

39. Zhang A, Yang WC, Ge Y, Wang YZ, Liu PH. Study on the hydration and moisture transport of white cement containing nanomaterials by using low field nuclear magnetic resonance. Constr Build Mater. 2020; 249: 118788.

40. Parrott LJ. Variations of water absorption rate and porosity with depth from an exposed concrete surface: Effects of exposure conditions and cement type. Cem Concr Res. 1992; 22: 1077-1088.

41. Patel RA, Perko J, Jacques D, De Schutter G, Ye G, Van Bruegel K. Effective diffusivity of cement pastes from virtual microstructures: Role of gel porosity and capillary pore percolation. Constr Build Mater. 2018; 165: 833-845.

42. Garboczi EJ, Bentz DP. Modelling of the microstructure and transport properties of concrete. Constr Build Mater. 1996; 10: 293-300.

43. Pandey SP, Sharma RL. The Influence of mineral additives on the strength and porosity of OPC mortar. Cem Concr Res. 2000; 30: 19-23.

44. Gruyaert E, Maes M, De Belie N. Performance of BFS concrete: K-Value concept versus equivalent performance concept. Constr Build Mater. 2013; 47: 441-455.

45. Rashidi M, Knapp MC, Hashemi A, Kim JY, Donnell KM, Zoughi R, et al. Detecting alkali-silica reaction: A multi-physics approach. Cem Concr Compos. 2016; 73: 123-135. 
46. Marinoni N, Voltolini M, Mancini L, Cella F. Influence of aggregate mineralogy on alkali-silica reaction studied by X-ray powder diffraction and imaging techniques. J Mater Sci. 2012; 47: 2845-2855.

47. Thomas M. The effect of supplementary cementing materials on alkali-silica reaction: A review. Cem Concr Res. 2011; 41: 1224-1231.

48. Santos MB, De Brito J, Silva AS. A review on alkali-silica reaction evolution in recycled aggregate concrete. Materials. 2020; 13: 2625.

49. Nagrockienè $D$, Rutkauskas $A$. The effect of fly ash additive on the resistance of concrete to alkali silica reaction. Constr Build Mater. 2019; 201: 599-609.

50. Yang MJ, Paudel SR, Asa E. Comparison of pore structure in alkali activated fly ash geopolymer and ordinary concrete due to alkali-silica reaction using micro-computed tomography. Constr Build Mater. 2020; 236: 117524.

51. Singh J, Singh SP. Evaluating the alkali-silica reaction in alkali-activated copper slag mortars. Constr Build Mater. 2020; 253: 119189.

52. Mavroulidou M. Mechanical properties and durability of concrete with water cooled copper slag aggregate. Waste and Biomass Valorization. 2017; 8: 1841-1854.

53. Najimi M, Pourkhorshidi AR. Properties of concrete containing copper slag waste. Mag Concr Res. 2011; 63: 605-615.

54. Xiao JZ, Lei B, Zhang CZ. On carbonation behavior of recycled aggregate concrete. Sci China Technol Sci. 2012; 55: 2609-2616.

55. von Greve-Dierfeld S, Lothenbach B, Vollpracht A, Wu B, Huet B, Andrade C, et al. Understanding the carbonation of concrete with supplementary cementitious materials: $A$ critical review by RILEM TC 281-CCC. Mater Struct Constr. 2020; 53: 1-34.

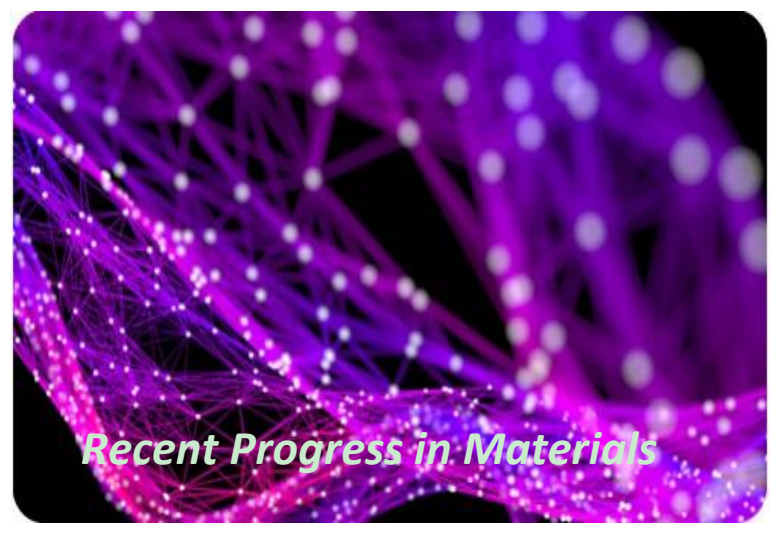

Enjoy Recent Progress in Materials by:

1. Submitting a manuscript

2. Joining in volunteer reviewer bank

3. Joining Editorial Board

4. Guest editing a special issue

For more details, please visit: http://www.lidsen.com/journals/rpm 